\title{
OS INCENTIVOS DO PROGRAMA GRANDE CARAJÁS ÀS GRANDES EMPRESAS E AS REPERCUSSÕES EM COMUNIDADES RURAIS
}

\author{
R.A. CASTRO \\ Instituto Federal de Educação, Ciência e Tecnologia do Maranhão \\ raifrancastro@ifma.edu.br
}

Artigo submetido em 23/01/2017 e aceito em 26/07/2019

DOI: $10.15628 /$ holos.2019.5573

\section{RESUMO}

Os programas de desenvolvimento regional são destaque em pesquisas de diversas áreas. No entanto, ainda são poucas as pesquisas que se dedicam à análise das repercussões destes no cotidiano de pequenas comunidades rurais. Com isso, $\mathrm{O}$ objetivo deste artigo é demonstrar como o Programa Grande Carajás (PGC) possibilitou o crescimento da mineradora Vale S/A, bem como a implantação da Suzano Papel e Celulose no Maranhão, e o crescimento da influência destas em comunidades rurais, como é o caso do Assentamento Francisco Romão, em Açailândia (MA), e das quebradeiras de coco babaçu da Reserva Extrativista (RESEX) Ciriáco, em Cidelândia (MA). Os resultados contribuem para que movimentos sociais do campo tenham maior conhecimento das repercussões destas relações, possam aperfeiçoar suas ações de formação de trabalhares rurais.

PALAVRAS-CHAVE: Programa Grande Carajás, Dominação Empresarial, Movimentos Sociais do Campo.

\section{THE REGIONAL DEVELOPMENT OF EASTERN AMAZONIA AND THE IMPACT IN RURAL COMMUNITIES}

\begin{abstract}
The regional development programs are highlighted in research in several areas. However, there are still a few searches that are dedicated to the analysis of the impact of the daily lives of small rural communities. With this, the aim of this article is to demonstrate how the projects for regional development can interfere in everyday life of these communities. We selected the Great Program Carajás (GPC), the gains of mining company Vale S/A and
\end{abstract}

the Suzano Papel e Celulose S/A, and their relations with the community of the Settlement Francisco Romão (Açailândia-MA) and the Extractive Reserve Ciriáco (Cidelândia - MA). The results contribute to that social movements have greater knowledge of the repercussions of these relations can improve their actions of formation of work in rural areas.

KEYWORDS: Great Program Carajás, Corporate Domination, Social Moviments Rural. 


\section{INTRODUÇÃO}

O desenvolvimento econômico de algumas regiões é foco de pesquisadores de diversas ciências sociais e humanas. Além disso, os representantes do Estado têm se empenhado em avaliar se estes projetos representaram ganhos econômicos. Ainda que representem uma parcela cada vez maior das pesquisas, são poucos os estudos que analisam os efeitos destes projetos de desenvolvimento regional no cotidiano de pequenas comunidades rurais, principalmente das localizadas em regiões sem grande destaque nacional.

O objetivo deste artigo é demonstrar como o Programa Grande Carajás (PGC) possibilitou o crescimento da mineradora Vale S/A, bem como a implantação da Suzano Papel e Celulose no Maranhão, e o crescimento da influência destas em comunidades rurais, como é o caso do Assentamento Francisco Romão, em Açailândia (MA), e das quebradeiras de coco babaçu da Reserva Extrativista (RESEX) Ciriáco, em Cidelândia (MA). O problema a ser tratado diz respeito à necessidade de se conhecer melhor as estratégias utilizadas pelas empresas na relação com as comunidades rurais.

Para cumprir o objetivo deste artigo foram realizadas entrevistas estruturadas, entrevistas não-estruturadas (Gil, 1996) e focalizadas (Marconi \& Lakatos, 2003), aos assentados e às quebradeiras de coco babaçu; com os representantes das duas empresas. Foram consultados: relatórios disponibilizados pelo Instituto Nacional de Colonização e Reforma Agrária (INCRA), pelas prefeituras de Açailândia, Cidelândia e Imperatriz, e pelo Instituto Chico Mendes de Conservação da Biodiversidade (ICMBio); relatórios disponibilizados pelas empresas; atas das reuniões realizadas pela comunidade; além de análises em campo.

A principal contribuição deste artigo é a demonstração de como os investimentos realizados nos últimos 30 anos têm repercutido na região do PGC, nos temas sociais e ambientais. Além de apresentar importantes análises sobre a ação empresarial atual no relacionamento com pequenas comunidades rurais. Os resultados contribuem para novos estudos sobre a relação entre empresas e comunidades; e para que os movimentos sociais do campo tenham melhores informações para aperfeiçoar suas ações de formação de trabalhares rurais.

\section{O PROGRAMA GRANDE CARAJÁS E O APOIO ÀS GRANDES EMPRESAS}

A Amazônia brasileira é destaque nos debates nacionais quando se conjugam as ações de incentivo ao desenvolvimento econômico, utilizando-se principalmente a exploração ambiental, e as repercussões ambientais e sociais destas. A porção oriental tem recebido maior destaque acadêmico e político, pois representa, como destacam Coelho e Monteiro (2007, p. 22) uma área de "[...] desestruturação e reestruturação socioespacial e físico ambiental impulsionada pela mineração industrial." Representação ampliada com o PGC, que é um dos exemplos de aplicação, no Brasil, das tradicionais teorias de desenvolvimento regional 
Um dos principais exemplos brasileiros da aplicação da teoria dos Polos de Crescimento ${ }^{1}$ é o PGC, que fez parte das ações do II Plano Nacional de Desenvolvimento (PND) ${ }^{2}$, como menciona Tavares (2013, p. 28). Os problemas sociais, culturais e ambientais, de todo o processo histórico de ocupação e de expansão econômica da região, foram e ainda são objetos de estudos. Dentre os pesquisadores que analisam o PGC, e suas repercussões na Amazônia, citam-se Ottati (2013), Monteiro (2012; 2006; 2004; 1998), Ab'Saber (2004), Anderson e Clay (2002), Diegues (1999), Castro (1994; 1992), Hébete (1991). É consenso que o Estado se destaca como um dos importantes agentes beneficiadores das grandes empresas.

A ação do Estado foi primordial para a realização do PGC. Como Marx (1996a, p. 423) enfatiza, nas primeiras etapas da produção de certas empresas, o Estado acaba subsidiando os primeiros investimentos. Para Marx (1996b, p. 118) “[...] o capital, assim que fica sujeito ao controle do Estado apenas em alguns pontos da periferia social, se ressarce tanto mais desmesuradamente nos outros pontos [...]". A relação entre o PGC e as colocações de Marx aqui citadas, diz respeito aos investimentos realizados no início deste, que foram realizados pelo Estado brasileiro. Mesmo que tenham beneficiado, prioritariamente, grandes empresas. Dentre elas tem-se a mineradora Vale S/A, e mais recentemente a Suzano Papel e Celulose S/A, instalada no município de Imperatriz (MA).

Para Sant'Ana Júnior et al. (2012) se têm diversos indicativos de que esta função, no caso do PGC e os empreendimentos instalados, seguiu trâmites tradicionais de beneficiamento empresarial. Os autores citam que o Estado atuou como beneficiador das empresas, através dos grandes projetos e "[...] oferecendo incentivos fiscais e financiamentos para novos investimentos, mas permanecendo cúmplice e corresponsável pelo impacto socioambiental" (Sant'Ana Junior, 2012, p. 188). Como destaca Andrade (2015), o objetivo maior era explorar os recursos naturais, justificando com uma suposta necessidade de ocupação do que seriam "espaços vazios".

Como destacam Castro e Santos (2016), o PGC atraiu milhares de famílias para a região, buscando emprego e habitação, que associado à instalação de aparatos industriais e logísticos, alterou significativamente a paisagem regional. Além de acentuar os problemas sociais urbanos (Rocha et al., 2015; Cruz et al., 2011).

Em termos de impactos nas áreas rurais, citam-se os conflitos agrários relacionados com a distribuição de terras sem claros critérios sociais (Bruzaça \& Sousa, 2015). Além da questão do Grupo Especial de Terras do Araguaia-Tocantins (GETAT), criado para reduzir o potencial de articulação dos trabalhadores rurais, e dos pequenos agricultores familiares na luta pela distribuição justa das terras (Pereira, 2016).

Citando o aparato financeiro e logístico aplicado pelo Estado brasileiro na região do PGC, para explorar as riquezas minerais, Bunker (2007, p. 134) o relaciona "[...] a um conjunto de ambiciosos programas para integrar o desenvolvimento industrial e agrícola, investindo

\footnotetext{
${ }^{1}$ Teoria desenvolvida por François Perroux a partir dos anos de 1950; segundo ele os polos de desenvolvimento são de grande importância para que uma determinada região alcance o desenvolvimento técnico e humano e passe a ocorrer uma colaboração entre áreas ricas e pobres (Lima \& Simões, 2010). Tem-se como algumas características: "[...] presença da indústria motriz inovadora, de grande dimensão, assimetria do polo em relação às unidades interligadas, presença implícita de um comandante, que faz a unidade motora crescer acima da média da economia, e crescimento descontínuo e desequilibrado." (Souza, 2005).

2 Plano que foi iniciado em 1974 pelo presidente Ernesto Geisel, e que tinha como principais objetivos aumentar a capacidade energética e a produção de insumos e bens de capital, onde o crescimento econômico seria induzido por fontes de matéria prima, como o minério no Pará (Fonseca \& Monteiro, 2007).
} 
pesadamente na construção de estradas, ferrovias, portos, hidrelétricas, linhas de transmissão, sistemas de comunicação e novas cidades inteiras [...]". Mas, para Azar (2013, p. 323) estes empreendimentos apoiados pelo Estado, "[...] desarticulam a organização social e produtiva das famílias camponesas [...]", e ainda "[...] estabelecem novas relações de trabalho e alteram a questão agrária."

Como já faz parte destes investimentos, os resultados positivos na economia ofucam a problemática social. Em contrapartida, relacionando os grandes projetos implantados no Maranhão, geradores de conflitos socioambientais, Tavares (2008, p. 213) destaca que "[...] quanto mais aparecem investimentos empresariais, os chamados grandes projetos, mais se explica a miséria da maioria da população." Barbosa (2013, p. 126), destaca ainda que, mesmo com todos os resultados econômicos, passados trinta anos do PGC "[...] o Maranhão continua sendo um dos estados mais pobres do Brasil, ostentando indicadores sociais baixíssimos e altos índices de concentração de terras, riquezas e poder político."

Além de não gerar os expressivos ganhos econômicos e sociais propalados na época da implantação, o PGC, ao ampliar a exploração dos recursos naturais do oeste maranhense, tornou a região em um "[...] corredor de problemas sociais [...]" com a construção da Estrada de Ferro Carajás (EFC), como destacam Palheta et al. (2015, p. 291). E como retrato dessa realidade tem-se a constante emigração de maranhenses para a região de Parauapebas (PA), buscando por vagas de empregos indisponíveis nos municípios maranhenses abrangidos pela EFC (Souza \& Eld, 2013).

Todo o investimento resultou em certo destaque econômico para a região do PGC. Como citam Fernandes e Negreiro (2004, p. 35), o Maranhão é destaque nas vendas internacionais, principalmente de commodities (minério de ferro, aço e celulose). Sobre este setor da economia, e seu crescimento no Maranhão, Borlina Filho (2011) destaca que a Suzano Energia Renovável já previa um investimento de 1 bilhão de reais em Imperatriz na formação de florestas, a partir da transformação de pastagens inutilizadas. Estes investimentos ampliaram o poder das grandes empresas na região, aumentando a capacidade de estabelecerem a territorialização empresarial na região do PGC.

\section{O PGC E AS ESTRATÉGIAS DAS GRANDES EMPRESAS}

No Brasil os projetos de desenvolvimento regional têm priorizado atividades relacionadas ao setor primário. Zhouri (2005) apresenta análises importantes, considerando que os investimentos na primarização das economias resultam na concentração de terras, no baixo nível de empregabilidade e de investimentos nas pequenas propriedades. Sendo estes relacionados com "[...] projetos envolvendo mineração, hidrelétricas, monoculturas de eucalipto, de soja, entre outros concentradores de grandes extensões territoriais." (Zhouri, 2005, p. 06).

Cita-se o exemplo mencionado por Sousa (2012, p. 240), que, prevendo a exaustão das minas de ferro de Carajás no Pará, o Estado e a mineradora Vale se empenham em resolver questões econômicas. Não se observa o mesmo esforço para a resolução dos problemas socioeconômicos que surgem, principalmente no meio rural. Os grandes projetos influem sobre a questão agrária da região, bem como nas comunidades rurais.

Sobre a inoperância do Estado, Guimarães (1998, p. 1534) menciona que este: “[...] usando de suas prerrogativas, sentindo-se mal colocado, perdido nos emaranhados burocráticos, pela 
disposição de acompanhar as exigências solicitadas pelos Sem Terra, declara que não deve ser apenas de sua responsabilidade as soluções da questão." Para Silva (2006, p. 129), no caso do Maranhão, a formação de assentamentos está relacionada mais à "[...] ação direta do movimento social organizado, e não de uma estratégia de desenvolvimento (políticas públicas) do poder público [...]".

Como no conflito entre comunidades rurais e empresas analisado por Esterci (1987), os agentes do Estado atuantes nestas situações de conflito dividem-se em dois grupos: os que arbitram em favor da empresa; e os que podem vir a fortalecer a capacidade de resistência da comunidade. O problema é que tem-se observado maior apoio às grandes empresas internacionais, como a Vale e Suzano.

Citando o caso do assentamento Califórnia, localizado no município de Açailândia - MA, Azar (2013) destaca que a articulação do agronegócio junto aos setores conservadores da sociedade, e a disseminação descaracterizada e distorcida do que seriam as práticas e o contexto político dos movimentos dos trabalhadores rurais, bem como da luta pelo direito à terra; patrocinada por estes que transmitem o discurso do que seria a "[...] incompetência da agricultura familiar camponesa [...]" (Azar, 2013, p. 152), acabam enfraquecendo o movimento. As grandes empresas passam para o processo de "[...] cooptação das famílias, seja inserindo-as na produção, com o trabalho direto, ou com o arrendamento dos lotes seja com projetos sociais ou com a relação direta com lideranças."

A questão agrária envolve uma série de problemas sociais, em destaque as questões políticas. Além disso, a recente aproximação com o setor empresarial torna esta realidade ainda mais complexa. Tem-se questionado a entrada destas nas comunidades, não apenas do ponto de vista social, mas também ambiental, considerando-se os danos causados, na medida em que priorizam a ampliação dos seus lucros. Preocupação ampliada quando esta relação é estabelecida com comunidades localizadas em áreas protegidas.

Uma das principais entradas de empresas em reservas extrativistas (RESEX) tem sido os acordos entre as empresas e as comunidades, para a execução de projetos de manejo florestal. Como exemplo, Martins (2008) cita que há diversos problemas nesta parceria, dentre elas a quase inexistente presença do Estado, necessitando assim de pesquisas mais aprofundadas que tratem destas relações.

A falta de políticas públicas adequadas tem reduzido a importância das unidades de conservação, como destaca Vallejo (2009). Citando a RESEX Ciriáco, Alexandre (2002, p. 16) menciona que estas áreas "[...] são somente explicadas levando-se em consideração o agravamento dos conflitos socioambientais relacionados com a expansão do domínio de propriedade privada típico dos modelos agrícolas e de pecuária brasileiros." Tem-se, portanto, a questão de uma histórica e tensa luta política e social pelo estabelecimento do poder sobre certas áreas.

Sobre a questão da territorialização da Vale, e dos seus investimentos na extração dos minérios do Pará, além do uso da EFC no Maranhão, Pantoja (2012, p. 42) destaca que "[...] a questão territorial emerge e se torna central, principalmente quando a discussão abarca os efeitos regionais dos impactos do complexo [...]". Complementando, o autor cita a empresa consegue "[...] configurar novas territorialidades no espaço político-social, uma vez que age articulando indivíduos, movimentos sociais, instituições e recursos de maneira a lhe permitir que, logo depois, possa agir sozinha em busca de seus objetivos." (Pantoja, 2012, p. 45). Considera-se que as ações desta empresa, na busca pelo não reconhecimento dos danos ambientais causados, bem como das punições sofridas, mostram seu poder político na região. 
As correlações de forças são paradoxalmente impostas diante dos interesses coletivos, principalmente quando se trata de conflitos entre grandes empresas/poderes públicos e as pequenas comunidades urbanas ou rurais. Nestes casos cita-se que, as corporações, ou os representantes do Estado, "[...] disputam entre si a autoridade/perícia legítima para arbitrar os conflitos especificamente ambientais." (Acselrad \& Bezerra, 2007, p. 20). Mas Araújo e Nóbrega (2014) citam, considerando a realidade da Amazônia maranhense, que existem movimentos rebelados, pois:

Percebe-se que, em busca do reconhecimento e da legitimidade de suas identidades coletivas, os povos e comunidades tradicionais, representados ou não por movimentos sociais, reinventam a mobilização e ação coletiva, atuando por dentro e fora do Estado. Sendo assim, a luta social muda de lugar, assim como também mudam as formas de mediação, processo que precisa ser melhor compreendido sociologicamente. Na Amazônia maranhense, nos últimos anos, as formas de pressão sobre o poder público e sobre empresas de iniciativa privada instaladas na região, têm sofrido variações, envolvendo grupos e agentes sociais diferenciados, quer seja por meio de ocupações de instituições públicas (STTR, quilombolas, MST), bloqueios de estradas e ferrovias (indígenas), marchas (mulheres, MST) (Araújo \& Nóbrega, 2014, p. 2201).

No Maranhão os conflitos socioambientais, combinados com deslocamentos compulsórios de aparatos logísticos, de plantas industriais e a respectiva migração populacional, se configuram desde o início dos anos 1980, e continuam a surgir novos. Isto se considerando as características impactantes do modelo de desenvolvimento dominante permanecem, mesmo que discursivamente amenizadas. Processo realizado com a incorporação de noções como desenvolvimento sustentável, sustentabilidade, responsabilidade social e ambiental (Mendonça, 2013; Sant'Ana Junior, 2009; Sant'Ana Junior et al., 2009). Nos dois casos analisados a seguir, se percebem claramente o uso dos investimentos financeiros para a redução da avaliação negativa das empresas, principalmente buscando a introdução de uma nova representação das duas empresas.

\section{O ASSENTAMENTO FRANCISCO ROMÃO E A RESEX CIRIÁCO}

Tratando-se da relação entre grandes empresas e comunidades rurais, destaca-se o caso dos investimentos realizados pela Suzano junto às quebradeiras de coco da Reserva Extrativista Ciriáco. Como fruto do estreitamento desta relação, ocorreu a construção de uma Unidade de Beneficiamento do Babaçu (UBB), e que também é utilizada para reuniões com os demais associados, ou apenas entre as quebradeiras. Este se tornou um símbolo positivo da relação com a empresa, ampliando a representação da Suzano como parceira, enquanto se observa um enfraquecimento do capital financeiro e jurídico do Estado na RESEX.

Segundo informações dos representantes do ICMBio e da Suzano, não existem documentos que tratem da construção da UBB. Tem-se os documentos de compra dos materiais necessários, e que estão em posse da empresa, e não foram disponibilizados. Esta obra não teve influência do Conselho de Desenvolvimento Comunitário (CDC) citado a seguir, pois este ainda não existia.

Os representantes do ICMBio citam que, para a UBB, a Suzano disponibilizou equipamentos como um computador, uma balança de precisão, lona, bombonas, mesa e cadeira. Além de materiais de construção como areia, esquadrilhas, pilares de ferro, cimento, telhas, piso, portas e 
janelas. A empresa também depositou $\mathrm{R} \$ 18.000,00$ (Dezoito mil reais) na conta da Associação dos Trabalhadores Agroextrativistas da Reserva Extrativista do Ciriáco (ATARECO), para pagamento dos pedreiros/ajudantes. Há ainda a recente doação de uma secadora de amêndoas do babaçu. Os valores não citados, são de responsabilidade da empresa, e não foram divulgados.

A Suzano repassa o recurso e a comunidade construiu a UBB. Depois disso a empresa potencializou seu capital simbólico positivo e amplia seu poder simbólico dentro da RESEX. Desde então as quebradeiras de coco avaliam que esta parceria pode trazer novos recursos, avaliando a relação com a empresa positivamente.

Uma característica desta relação que merece destaque, é o fato da empresa ter incentivado a formação de um "Conselho de Desenvolvimento Comunitário - CDC)" ${ }^{3}$. Este conselho tem como finalidade potencializar a relação entre ela e as comunidades da chamada região da "Estrada do Arroz". Com a formação e formalização deste, a Suzano prioriza que qualquer tipo de relação com as comunidades seja realizada por meio deste, acompanhada pelas associações das comunidades.

A Suzano sabendo da sua simbologia negativa junto às comunidades, e prevendo possíveis relações conflituosas, contrata pessoas com histórico ligado às comunidades. Com isso as quebradeiras de coco transferem para a empresa a confiança que têm na pessoa que atualmente trabalha para a Suzano, e que anteriormente foi ligada ao Estado (ICMBio).

A empresa passa a apresentar os recursos de responsabilidade social como meio para se investir na comunidade, vinculando-se aos possíveis ganhos com o fortalecimento financeiros dos projetos de beneficiamento de babaçu. As quebradeiras de coco consideram que receber recursos da empresa pode trazer ganhos para a comunidade, pois são poucos os resultados positivos com o Estado.

No ano de 2012, a empresa implanta o projeto "Extrativismo Vegetal", visando ampliar o extrativismo na região, complementando ainda com os "[...] demais sistemas produtivos de agricultura familiar, proporcionando aos grupos participantes - em especial povos e comunidades tradicionais - condições de desenvolvimento local e fortalecimento da produção rural." (Suzano, 2012, p. 83). Projeto implantado na Ciriáco e em demais comunidades da Área de Influência Direta (AID) da empresa. A maneira como esta atua nas comunidades é descrita da seguinte forma:

Além de a matéria-prima ser totalmente coletada em nossas áreas, apoiamos o projeto com a promoção de reuniões para a definição de ações de fortalecimento da produção, como a doação de máquina forrageira para trituração do coco e reforma e ampliação da sede da entidade, onde a comunidade se reúne e participa de curso de capacitação e treinamentos (Suzano, 2012, p. 83).

Um exemplo importante do conflito simbólico envolvido na relação entre esta empresa e as comunidades da região, é apresentado pelo PNCSA (2014). Tem-se a fala de uma quebradeira de coco da reserva, representante do MIQCB, e que se afastou das demais quebradeiras da RESEX. Tem-se que:

[...] É uma parceria da Suzano, ICMBio com a ATARECO e tem outra em Petrolina, que vão construir, que é de mesocarpo. Somente eu fui contra essa parceria que sei ser complicada, pois a Suzano é a mesma Celmar e comprou as terras, está comprando tudo aqui, então a

\footnotetext{
${ }^{3}$ A RESEX Ciriáco tem duas quebradeiras de coco na coordenação deste conselho, representando as demais da reserva.
} 
situação é essa carvão queimando direto, de coco inteiro (...) todo mundo tem conhecimento de que a Suzano não é diferente, é a mesma Celmar, e nos aqui somos prejudicados pela Celmar que é a mesma Suzano, aqui nós estamos tomados, então a gente... já teve audiência sobre essa questão da Suzano e ela é a mesma Celmar que a gente tem conhecimento, ela só veio nos prejudicar [...] (PNCSA, 2014, p. 06).

Tratando-se das interferências impulsionadas pela rede logística de grandes empresas em comunidades rurais, cita-se o caso do uso da Estrada de Ferro Carajás pela mineradora Vale S/A, e sua interferência no cotidiano na agrovila do Assentamento Francisco Romão. Para complementar a análise das estratégias utilizadas nesta relação, utiliza-se a reunião realizada no dia 04 de dezembro de 2012 na comunidade ${ }^{4}$. A fonte das informações aqui citadas é uma ata da reunião cedida pela empresa, que foi realizada com a participação de representantes das comunidades do Novo Oriente, Planalto I, Agroplanalto, João do Vale, Associação Boa Esperança, do Sindicato dos Trabalhadores Rurais, e do assentamento aqui analisado, o Francisco Romão (AFR). O grupo constituído pelos representantes da empresa e da comunidade é denominado de Comitê de Interlocução $(\mathrm{Cl}){ }^{5}$

Esta reunião está relacionada com um levantamento realizado em campo pelos funcionários da Vale, especificamente do setor de relacionamento com comunidades. Ao identificarem em campo que havia a possibilidade da ampliação do conflito com os trabalhadores rurais da região. Houve um desencontro das informações entre a demanda apresentada pela comunidade, e a execução pela empresa, principalmente sobre as obras de piçarramento das estradas vicinais. Solicitação feita durante uma grande manifestação realizada ainda em janeiro de 2012.

Em um relatório denominado "Gestão de Issues no Maranhão - Mobilização de lideranças de Novo Oriente contra a Vale", cedido pela equipe da empresa, recomendou-se a retomada dos processos de diálogo, e a realização de convênios que reduzissem a tensão entre as comunidades e a empresa. Neste documento foram citados como stakeholders ${ }^{6}$ envolvidos: a Justiça nos Trilhos; lideranças comunitárias; o vice prefeito de Açailândia; o MST. Já previa-se neste documento um investimento de $\mathrm{R} \$ \mathbf{8 0 0 . 0 0 0 , 0 0}$ (oitocentos mil reais) na região.

De acordo com a ata da reunião citada acima, as pautas foram: comunicação da obtenção da Licença de Instalação, referente à DEFC; apresentação das propostas da Vale; conversa com as liderança; definição das próximas etapas, onde no texto cita-se "juntos"; definição da data da próxima reunião. Os representantes do AFR participaram da reunião, mas neste momento não receberam benefícios diretos, pois em reuniões entre as comunidades, definiu-se que as outras comunidades menos atendidas pelo Estado seriam beneficiadas neste momento.

Tem destaque na ata da reunião, que o piçarramento destinado aos assentamentos Francisco Romão e João do Vale não foi concluído. Onde uma liderança destacou a importância deste serviço para as comunidades, e que as 150 horas de trabalho financiadas pela empresa Vale

\footnotetext{
${ }^{4} \mathrm{O}$ relacionamento desta comunidade com a mineradora Vale teve início ainda em 2010, quando a construtora Odebrecht inicia a instalação de um canteiro de obra na comunidade Novo Oriente, próxima do Francisco Romão. Mas neste artigo são enfatizados os principais acontecimentos posteriores à grande manifestação de 19 de janeiro de 2012 , que é detalhada por Ferreira (2013).

${ }^{5} \mathrm{O}$ "Guia de Relacionamento com Comunidades (GRC)", cedido por representantes da empresa, cita que estes comitês são fruto de uma determinação do Instituto Brasileiro do Meio Ambiente e dos Recursos Naturais Renováveis (IBAMA), para que fosse realizado o processo de licenciamento da obra da expansão da EFC. Neste GRC estes comitês são apresentados como "Melhores práticas" de diálogo social da empresa.

${ }^{6}$ No contexto das grandes corporações, são as partes interessadas.
} 
não foram o suficiente para realizar o trabalho completo. Como explicação, um representante da empresa, citou que uma nova solicitação seria encaminhada aos diretores. Este completou ainda que estas demandas serão tratadas como produtos, e não mais como horas de trabalho. Neste momento se apresentou a proposta de que as reinvindicações de cada comunidade fossem apresentadas separadamente, devido às realidades de cada uma.

Um dos representantes da comunidade AFR citou que a região deve ser priorizada, pois esta sofre com os impactos da operação da EFC, e que com a duplicação os problemas piorarão. O mesmo solicitou que a empresa realizasse projetos de qualificação de mão de obra para os jovens. 0 representante da empresa solicitou que fosse encaminhada a proposta para a Vale.

A Vale apresentou três possibilidades de investimento nas comunidades, a serem realizados através de Termos de Cooperação (TC) ${ }^{7}$ entre a empresa, a prefeitura e as associações: construção de quadras esportivas; perfuração de poços artesianos; doação de tubulação para distribuição de água.

De acordo com o documento "Comunidades Críticas: Novo Oriente - Açailândia" (Vale, 2013), de 20 de maio de 2013, cedido pela equipe da empresa, a Vale classificava a região como área crítica em termos de relacionamento. No mesmo documento se tem um "Plano de Ação" destinado às ações nas comunidades desta área.

Tem-se que "A comunidade recebe impactos da Operação e Expansão. Em fevereiro de 2013 foi desinstalado um canteiro da Expansão EFC, que estava dentro da comunidade de Novo Oriente." (Vale, 2013, p. 03). Neste documento também são observados as seguintes informações de avaliação da região:

Devido à recente formação e a restrição 8 para receber investimentos do INCRA, boa parte destas comunidades possui acessos de má qualidade, escolas improvisadas com infraestrutura precária e dificuldades para acessos a serviços públicos básicos como água e saúde. É essencial apoiar algumas das solicitações desta comunidade que está solicitando o apoio da Vale desde 2011. A comunidade está crescendo próxima a ferrovia e como tratase de assentamentos e em área rural vivem em condições de grande vulnerabilidade. Os investimentos devem ser suportados pelos canais de diálogo com as comunidades. O grupo não permite realizar o registro fotográfico das reuniões de lideranças (Vale, 2013, p. 03).

O "Plano de Ação" cita que, para contemplar as demandas dos poços, das quadras e da distribuição de água citadas acima, foi aprovado um investimento de $\mathrm{R} \$ 950.419 .14$ (Novecentos e cinquenta mil, quatrocentos e dezenove reais e quatorze centavos), proveniente da verba do Programa de Capacitação Logística Norte (PCLN) ${ }^{9}$. Cita-se que estava aguardando apenas assinatura do convênio. Na época o recurso destinado ao empiçarramento/melhoria de vias, que seria proveniente da DIRC ainda não tinha sido aprovado. Seria um valor aproximado de $\mathrm{R} \$ 500.000,00$ (Quinhentos mil reais).

\footnotetext{
${ }^{7}$ Apesar do destaque dado pela empresa a este instrumento de gestão dos investimentos, o mesmo foi alterado para o "Termo de doação com encargos". Este foi assinado apenas pelos representantes da empresa e pelos representantes da comunidade.

${ }^{8}$ Esta restrição se relaciona com à regularização da comunidade como assentamento.

${ }^{9}$ Termo utilizado pela Vale para se referir ao conjunto de obras que têm como objetivo ampliar a capacidade de exportação do minério da S11D (mina recentemente descoberta). Envolve as obras da expansão da Estrada de Ferro Carajás e a ampliação do Terminal Ferroviário de Ponta da Madeira, além de um Ramal Ferroviário Sudeste do Pará.
} 
Outras reuniões do $\mathrm{Cl}$ foram realizadas nos dias 19 de fevereiro, no Francisco Romão, e 26 de março de 2013, realizada no Planalto I. Foram cedidas pelas empresas as listas de frequências e um resumo da ata. Na reunião do dia 19 de fevereiro foram analisados os cronogramas para execução das obras, os orçamentos, os textos dos convênios. No dia 26 de março foram analisadas as pendências, os documentos e a reelaboração dos cronogramas.

No documento "DIRC/EFC Comunidades Prioritárias" (Vale, 2015), cedido por representantes da empresa, se tem um demonstrativo dos investimentos realizados pela Vale na região do Novo Oriente, que abrange o Francisco Romão. São citadas algumas interferências a serem realizadas na região, como passarelas e viadutos, e a localização das comunidades.

Na publicação “A Vale no Maranhão” (Vale, 2014, p. 34), a empresa cita que a Fundação Vale "[...] implantou poços artesianos e sistema de distribuição de água [...]" nos assentamentos Francisco Romão e João do Vale. De fato esse investimento foi realizado em convênio com a "Associação dos Pequenos Produtores Rurais Boa Esperança do Assentamento Francisco Romão" (APPRBE-AFR). Este investimento ocorreu em 2014, e foi resultado d manifestação de janeiro de 2012.

Em 2016 a comunidade cobrou um trator de esteira para viabilizar as atividades agrícolas. No contexto da Vale, esta solicitação foi enquadrada como parte do "Plano de Relacionamento com Comunidades (PRC)", gerenciado pela Diretoria de Relacionamentos com Comunidades (DRC) situadas nas proximidades da EFC. Este investimento foi realizado em parceria com o SEBRAE, que fez a avaliação para implantação de programas de geração de renda.

Segundo informações da empresa, este trator faz parte dos investimentos considerados como um "Kit Agrícola". O recurso é próprio da empresa e considerado como "investimento voluntário". Em princípio a comunidade entregou um orçamento no valor de $\mathrm{R} \$ 118.000,00$ (Cento e dezoito mil reais), mas este não foi aprovado. Após uma avaliação da equipe da empresa, acertouse o valor de $\mathrm{R} \$$ 83.250,00 (Oitenta e três mil e duzentos e cinquenta reais). O recurso foi repassado à AFR ainda em julho de 2016, e o trator foi adquirido. Está em fase de uso pela comunidade. "Investimentos" que têm resultado em significativos ganhos simbólicos para a empresa, resultando na sua dominação diante da comunidade do Assentamento Francisco Romão.

\section{CONCLUSÃO}

A partir das informações e análises apresentadas, vislumbram-se duas realidades: a confirmação de que os programas de desenvolvimento regional, neste caso em destaque o PGC, têm beneficiado os grandes projetos econômicos; além disso, relacionam-se, ainda nos dias atuais, no crescimento do poder empresarial diante das pequenas comunidades. Mas é importante mencionar que mudanças importantes têm sido adotadas por estas corporações.

As alterações de estratégia destas empresas, considerando-se os dois casos analisados, são: se antes as empresas iniciavam suas ações sem avaliar os possíveis danos às comunidades circunvizinhas, hoje, além de ser uma obrigação legal, elas realizam constantes estudos que visam reduzir estes danos, e consequentemente, as relações conflituosas; tem-se também que os recursos financeiros não são apenas repassados às comunidade, pois há um importante trabalho de transformação destes investimentos em ganhos simbólicos, principalmente na busca por representações empresariais mais positivas; e, principalmente, busca-se reduzir a rede de relações das comunidades, para que a relação ocorra estritamente entre a empresa e os trabalhadores rurais. 
Contribui-se com este artigo, para que se acrescentem nos atuais, e próximos estudos sobre grandes projetos de desenvolvimento regional, e sobre a relação entre as empresas e as comunidades das suas cercanias a necessidade de detalhamento das estratégias utilizada spelas grandes corporações. As análises aqui citadas devem ser utilizadas pelos movimentos sociais, principalmente os do campo, nos momentos de formação. Isto amplia a capacidade de articulação e de luta política e simbólica diante das estratégias empresariais.

\section{REFERÊNCIAS}

Ab'Saber, A. N. (2004). A Amazônia: do discurso à práxis. 2ª ed. São Paulo EdUSP.

Acselrad, H., \& Bezerra, G. N. (2007). Inserção Econômica Internacional e "Resolução Negociada" de conflitos ambientais na América Latina. Recuperado em 12 de julho, 2014, de http://goo.gl/BCJg5o.

Alexandre, A. F. (2002). A política que se apreende: avaliando o processo de implementação das reservas extrativistas no Brasil à luz do ideário da etnoconservação. Cadernos de Pesquisa Interdisciplinar em Ciências Humanas, 3 (25), 2-19. Recuperado em 20 de junho, 2015, de http://migre.me/vrDhQ.

Anderson, A. B., \& Clay, J. W. (2002). Esverdeando a Amazônia: comunidades e empresas em busca de práticas para negócios sustentáveis. São Paulo: Editora Peirópolis.

Andrade, G. P. (2015). A Amazônia e o Projeto Grande Carajás: entre as tentativas de desenvolvimento da região e os problemas causados às populações indígenas. Mundo Amazónico, 6 (2), 5 - 19. Recuperado em 22 de janeiro, 2016, de http://dx.doi.org/10.15446/ma.v6n2.52950.

Araújo, H. F. A., \& Nóbrega, M. L. C. (2014). Empreendimentos agroindustriais, ações coletivas de povos e comunidades tradicionais, conflitos territoriais e socioambientais. Anais do Congresso Iberoamericano de Estudios Territoriales y Ambientales, São Paulo, SP, Brasil, 6. Recuperado em 12 de fevereiro, 2016, de http://migre.me/vrF07.

Azar, Z. S. (2013). Relações de trabalho e resistência camponesa do desenvolvimento dependente no Maranhão: o assentamento Califórnia como uma expressão. Tese de Doutorado, Universidade Federal do Maranhão, São Luis, MA, Brasil.

Barbosa, Z. M. (2013). O global e o regional: a experiência de desenvolvimento no Maranhão contemporâneo. Revista Brasileira de Desenvolvimento Regional, 1(1). 113 - 128. Recuperado em 20 de janeiro, 2015, de http://dx.doi.org/10.7867/2317-5443.2013v1n1p113-128.

Borlina Filho, V. (2011). Commodities - Florestas avançam por novas fronteiras. Recuperado em 12 de março, 2014, de http://goo.gl/kgJAnG.htm.

Bruzaca, R. D., \& Sousa, M. T. C. (2015). Conflitos socioambientais no contexto desenvolvimentista da Amazônia brasileira: proteção de direitos de comunidades quilombolas no Maranhão frente à duplicação da Estrada de Ferro Carajás. Veredas do Direito, 12 (24), 147-173. Recuperado em 12 de junho, 2016, de http://migre.me/vs1vQ.

Bunker, S. G. (2007). Da Castanha do Pará ao ferro: os múltiplos impactos do projeto de mineração na Amazônia brasileira. In: Coelho, M. C. N., \& Monteiro, M. A. (Org.). Mineração e reestruturação da Amazônia. Belém: Editora NAEA, 105 - 140.

Castro, E. M. R. (1994). Industrialização, Transformações sociais e mercado de trabalho. Papers do NAEA, 23, $01-21$. 
Castro, E. M. R. (1992). Grande Carajás: Nascimento de um Pólo Guseiro em Açailândia, Maranhão. Cadernos do Centro de Estudos e Ação Social (CEAS), 142, 74-85.

Castro, R. A., \& Santos, O. C. O. S. (2016). Atividades econômicas e alterações no uso e ocupação do solo na bacia do córrego Água Branca, Açailândia (MA). Caminhos de Geografia, 17(57), 118 - 130.

Coelho, M. C. N., \& Monteiro, M. A. (Org.). (2007). Mineração e reestruturação espacial na Amazônia. Belém: NAEA.

Cruz, S. H. R., Castro, E. M. R., \& Sá, M. E. R. (2016) Grandes projetos urbanos em metrópoles amazônicas: modernização e conflito. Novos Cadernos NAEA, 14 (2), 135-151.

Diegues, A. C. (Org.). (1999). Desmatamento e modos da vida na Amazônia. São Paulo: NUPAUB.

Esterci, N. (1987). Conflito no Araguaia: peões e posseiros contra a grande empresa. Petrópolis: Vozes.

Fernandes, A. C., \& Negreiros, R. (2004). Desenvolvimento econômico, divisão de trabalho e mudanças na rede urbana. In: Fernandes, E.; Valença, M. M. (Org.). Brasil Urbano. Rio de Janeiro: Mauad. $25-56$.

Ferreira, C. C. (2013). Vozes da Terra: o diálogo como tática para a construção de relações em rede. Dissertação de Mestrado, Universidade Federal do Ceará, Fortaleza, CE, Brasil.

Fonseca, P. C. D., \& Monteiro, S. M. M. (2007). O Estado e suas razões: o II PND. Revista de Economia Política, 28 (1), $28-46$.

Gil, A. C. (1996). Como elaborar projetos de pesquisa. 3a ed. São Paulo: Atlas.

Guimarães, M. L. L. (1998). Assentamentos rurais sob políticas públicas com a empresa privada: assentamento Hipólito no município de Mossoró/RN. Anais do XI Encontro Nacional da ABEP, Campinas, SP, Brasil, 11. Recuperado em 22 maio, 2015, de http://www.abep.nepo.unicamp.br/docs/anais/PDF/1998/a185.pdf.

Hébette, J. (Org.). (1991). O cerco está se fechando: o impacto do grande capital na Amazônia. Petrópolis: Vozes.

Lima, A. C. C., \& Simões, R. F. (2010). Teorias clássicas do desenvolvimento regional e suas implicações de política econômica: o caso do Brasil. RDE, 12 (21), 5 - 19.

Marconi, M. A., \& Lakatos, E. M. (2003). Fundamentos de Metodologia Científica. 5a Edição. São Paulo: Editora Atlas.

Martins, D. P. (2008). Novos caminhos e antigas práticas: acordos de Comunidades com empresas para o manejo Florestal, o caso da reserva extrativista rio Preto-Jacundá em Machadinho D'Oeste RO. Dissertação de Mestrado, Universidade Federal do Pará, Belém, PA, Brasil.

MARX, K. (1996a). O capital: crítica da economia política. v. 01. Capítulos I-XII. (R. Barbosa., \& F. R. Kothe, Trad.). São Paulo: Ed. Nova Cultural.

(1996b). O capital: crítica da economia política. v. 02. Capítulos XIII - XXV. (R. Barbosa., \& F. R. Kothe, Trad.) São Paulo: Ed. Nova Cultural.

Monteiro, M. A. (2012). Mineração, siderurgia e desenvolvimento regional. Anais da Reunião anual da SBPC, São Luís, MA, Brasil, 64. Recuperado em 26 de março, 2015, de http://goo.gl/WtEouY. 
Monteiro, M. A. (2005). Meio século de mineração industrial na Amazônia e suas implicações para o desenvolvimento regional. Estudos Avançados, 19 (53), 187-207.

Monteiro, M. A. (2004). Amazônia: mineração, tributação e desenvolvimento regional. Novos Cadernos NAEA, 7 (2), $159-186$.

Monteiro, M. A. (1998). Siderurgia e Carvoejamento na Amazônia. Drenagem energético- material e pauperização regional. Belém: Editora da UFPA em co-edição com a ETFPA.

Ottati, A. M. A. A. (2013). As dinâmicas e as desigualdades regionais de desenvolvimento no estado do Maranhão. Tese de Doutorado, Universidade Federal do Rio Grande do Sul, Porto Alegre, RS, Brasil.

Página Sustentável. (2014). Suzano fortalece a cadeia produtiva do coco babaçu. Notícia Publicada em 18 dez. 2014. Recuperado em 23 de março, 2015, de http://goo.gl/VPVpSB.

Palheta, J. M., Silva, C. N., \& Medeiros, G. N. (2015). Territórios com mineração na região sudeste do Pará-Norte do Brasil. Revista da ANPEGE, 11 (15), 281-308.

Pereira, A. R. (2016). A Igreja Católica, o Sindicato dos Trabalhadores Rurais e o Estado: Mediação e Conflito na região Araguaia Paraense. Cadernos do CEAS, 232, p. 5-26.

PNCSA. (2014). Programa Nova Cartografia Social da Amazônia. A devastação dos babaçuais e a desestruturação de modos de vida dos povos e comunidades tradicionais. Boletim Informativo.

Rocha, M. R. V. S., Silva, D. C. O., \& Loiola, E. (2015). Amazônia Oriental: impactos socioambientais em Pequiá de Baixo no Município de Açailândia-Ma. Revista Acta Ambiental Catarinense, 12 (1/2), 17-30.

Sant'Ana Júnior, H. A., Milanez, B., Scotto, G., Bossi, D., \& Fato, K. (2012). Injustiça Ambiental, Mineração e Siderurgia. In: Porto, M. F., Pacheco, T., \& LEROY, J. P. (Org.). Injustiça Ambiental e Saúde no Brasil, o mapa de conflitos. Rio de Janeiro: Editora FIOCRUZ, 175-205.

Sant'Ana Júnior, H. A. (2009). Conflitos socioambientais no Maranhão e sua relação com grandes projetos de desenvolvimento. Anais da Jornada Internacional de Políticas Públicas, São Luís, MA, Brasil, 4.

Sant'Ana Júnior, H. A., Pereira, M. J. F., Alves, E. J.P., \& Pereira, C. R. A. (2009) Ecos dos conflitos socioambientais: a RESEX Tauá-Mirim. São Luis: EDUFMA.

Silva, J. R. S. (2006). Segurança alimentar, produção agrícola familiar e assentamentos de reforma agrária no Maranhão. Tese de Doutorado, Universidade Federal do Maranhão, São Luís, MA, Brasil. Souza, A. S., \& Eld, F. (2015). Migração de trabalhadores nordestinos a Parauapebas. Revista Geonorte, 4 (12), 1582-1599.

Sousa, R. V. (2012). A influência do Estado no crescimento da economia do setor mineral: o caso da CVRD de 1942 a 2010. Tese de Doutorado, Universidade Federal do Pará, Belém, PA, Brasil.

Souza, N. J. (2005). Teoria dos polos, regiões inteligentes e sistemas regionais de inovação. Análise, $16(1), 87-112$.

Suzano. (2012). Relatório de Sustentabilidade 2012. Recuperado em 20 de junho, 2015, de http://goo.gl/R55IcX.

Tavares, H. M. 2013. Estratégias de Desenvolvimento Regional: abordagens e experiências em tempos e espaços diferentes. In: Randolph, R., \& Tavares, H. M. (Org.). Política e Planejamento Regional: uma coletânea. Brasília: Gráfica Movimento. 22 - 30. 
Tavares, J. C. (2008). Universalidade e singularidades do espaço transitório: um estudo a partir de quebradeiras de coco Babaçu/MIQCB e trabalhadores rurais sem terra/MST no Maranhão (1990 2000). Tese de Doutorado, Universidade de Santa Catarina, Florianópolis, SC, Brasil.

Vale. (2015). Diretoria de Relacionamento com Comunidades. Estrada de Ferro Carajás. Comunidades Prioritárias. (No prelo).

Vale. (2014). A Vale no Maranhão. Recuperado em 22 de setembro, 2016, de http://migre.me/v2J2t. Acessado em: 22 de setembro de 2016.

Vale. (2013). Diretoria de Relacionamento com Comunidades. Comunidades Críticas - Novo Oriente (Açailândia). (No prelo).

Vallejo, L. R. (2009). Unidade de conservação: uma discussão teórica à luz dos conceitos de território e políticas públicas. Geographia, 4 (8), 57-78.

Zhouri, A. (2005). Conflitos sociais e meio ambiente urbano. Comunidades, Meio Ambiente e Desenvolvimento, 17. Recuperado em 12 de julho, 2015, de http://migre.me/uUPIJ. 